\title{
Sin noticias de arquitectas en España. Una aproximación feminista a la profesión y formación arquitectónicas desde la ilustración hasta la titulación de Matilde Ucelay
}

\author{
No News from Women Architects in Spain. A Feminist \\ Approach to the Architectural Profession and Education, \\ from the Enlightenment to Matilde Ucelay Degree
}

\begin{abstract}
RESUMEN
La titulación de Matilde Ucelay en 1936 como la primera arquitecta española establece un marco temporal de más de ciento ochenta años sin noticias de arquitectas desde que la formación en arquitectura se regulara en España con la creación de la Real Academia de San Fernando en 1752. Nos preguntaremos sobre las razones de esta ausencia, lo que nos llevará a estudiar de manera crítica el contexto social de creación de las redes e instituciones arquitectónicas, esto es, Academia, Escuelas de Arquitectura y Colegios Oficiales de Arquitectos. Se intentará fijar así las características que han formalizado las bases de la enseñanza y ejercicio profesional de la arquitectura con el objetivo de desvelar aquellos parámetros que alejaron a las mujeres del ámbito arquitectónico. Una ausencia femenina que el régimen franquista intentó perpetuar al relegar a Matilde Ucelay al ejercicio privado de la profesión y así conseguir que ningún edificio público recordase a la primera arquitecta española.
\end{abstract}

Palabras clave: Arquitectas; Matilde Ucelay; Perspectiva feminista; Arte útil; élite profesional.

\begin{abstract}
Matilde Ucelay's degree in 1936 as the first Spanish woman architect sets a timeframe of over one hundred eighty years with no news from women architects since regulation of architectural education in Spain after the creation of the Royal Academy of San Fernando in 1752. We ponder the reasons behind this lack of women, which leads us to a critical study of the social context of the creation of architectural networks and institutions, meaning the Academy and Schools of Architecture. Thus, an attempt will be made to define the characteristics that shaped the foundation for the teaching and professional practise of architecture, in order to reveal the parameters that distanced women from the architectural sphere. The Francoist regime sought to perpetuate this lack of women by relegating Matilde Ucelay to private practise of the profession, so that no public building would remember the first woman Spanish architect.

Keywords: Woman architects; Matilde Ucelay; Feminist perspective; Useful art; professional elite.
\end{abstract}




\section{SUMARIO}

1.-Introducción; 2.- Academia e Ilustración en España. Cuando la Arquitectura se convirtió en un Arte útil.; 3.- El afianzamiento de la élite profesional arquitectónica en la España del siglo XIX ; 4.- Noticias de Matilde Ucelay. La prohibición del ejercicio público de la profesión del primer «arquitecto femenino»; 5.-Conclusiones; 6.-Bibliografía

\section{SUMMARY}

1.-Introduction; 2.-Academy and Enlightenment in Spain. When Architecture Became a Useful Art; 3.- Consolidation of the architectural professional elite in Spain in the 19th century; 4.- News from Matilde Ucelay. The prohibition on the first «woman architect» to publicly practise her profession; 5 .- Conclusions; 6.-Bibliography

\section{1.- Introducción}

Citar a Matilde Ucelay no sólo supone referirse a la primera arquitecta titulada en España. Su egreso por la Escuela de Madrid en 1936 establece un marco temporal de más de ciento ochenta años sin noticias de arquitectas desde que la formación académica de la arquitectura se reguló en España con la formación de la Real Academia de San Fernando en 1752. En efecto, sabemos que no hubo mujeres que estuvieran matriculadas en la sección de Arquitectura de la Academia ni en las primeras Escuelas de Arquitectura que se fundaron a mediados del siglo XIX en Madrid y Barcelona. Ello nos lleva a preguntarnos sobre las razones de esta ausencia puesto que no parece que existiera una normativa específica que prohibiese el acceso femenino a las instituciones de enseñanza de la arquitectura. Siendo la Arquitectura una de las Bellas Artes tomaremos como punto de partida la línea discursiva que estableció Griselda Pollock en 1988 -tras la trazada en 1971 por Linda Nochlin- al preguntarse sobre la ausencia de las mujeres en el arte y en la historia del arte. Para Pollock la historia del arte se centra en un único individuo que, obviamente, es un hombre -y no una mujer- que crea una obra de arte. Así para la feminista «la figura central del discurso de la historia del arte es el artista, quien es presentado como un ideal inefable que complemente los mitos burgueses de un Hombre sin clase, universal» que «siempre superará los obstáculos sociales» (Pollock, 1988: 24,57). El ámbito de la Arquitectura comparte esta figura recurrente del «arquetipo de creador héroe solitario enfrentado a un entorno hostil» (Álvarez Benito y Galán Conde, 2007: $49 \mathrm{~b})$ tanto en el relato de la historiografía de la arquitectura como en el imaginario arquitectónico. Una de las primeras en denunciarlo públicamente fue la arquitecta Denise Scott Brown en un texto -escrito en 1973 y que sin embargo no se publicó hasta 1989- donde el ejercicio de la arquitectura es definido como un club de caballeros y el arquitecto como «macho revolutionary» (Scott Brown, 1989: 36). Para Inés Sánchez de Madariaga, una de las arquitectas que más ha investigado sobre arquitectura y género en España, ello es debido a que la historia de la arquitectura ha centrado su objetivo en elegantes monografías dedicadas a los arquitectos varones convirtiendo la biografía en «hagiografía» (2012b:433) donde el relato unipersonal sobre la figura del 
genio creador del proyecto arquitectónico no admitía compañeras de equipo. Zaida Muxí y Josep Montaner (2015:112-113) subrayan la existencia de estos mecanismos historiográficos, comunes en la construcción general de la historia, consistentes en fomentar el mito de la creación y la enfatización de la figura masculina. Ello lleva a una historia de individualidades y no de colectivos por lo que los colaboradores, pero sobre todo las colaboradoras, son borradas dificultando o imposibilitando su rastreo en la historiografía. Así, por ejemplo, los arquitectos Walter Gropius y Mies van der Rohe (ambos directores de la reconocida y vanguardista Escuela de Diseño Bauhaus) o el archiconocido Le Corbusier trabajaron de manera puntual con mujeres -arquitectas, decoradoras o diseñadoras- en su estudio profesional, lo que les granjeó un perfil de profesionales modernos e igualitarios. Sin embargo, las arquitectas que trabajaron con ellos -como Eileen Gray, Lily Reich o Charlotte Perriand- podrían ofrecernos un relato muy diferente. Eileen Gray, por ejemplo, sufrió un acto de «colonización», «ocupación» y «vandalismo» (Colomina, 2000: 10) por parte de Le Corbusier en su propia casa llamada E1027. Construida y diseñada por ella en 1926 en Cap Martin (Francia), las paredes de la casa fueron pintadas por parte de Le Corbusier -en ausencia y sin el permiso de la arquitecta- en un acto calificado por la arquitecta Beatriz Colomina de «violación» (2000: 10). Además, Le Corbusier publicó estos murales sin mencionar a Eileen Gray atribuyéndose de manera consecuente la autoría de la vivienda. Este arquitecto fue asimismo quien envió la conocida respuesta "desgraciadamente, en este taller no bordamos cojines» (Espegel, 2006:198) a la diseñadora Charlotte Perriand cuando esta solicitó ingresar en su estudio de arquitectura. Por su parte, la arquitecta Lily Reich es reconocida ya como la coautora del Pabellón de Barcelona junto con Mies van der Rohe y de casi todo el mobiliario atribuido -hasta ahora- únicamente a Mies. En España Margarita Mendizábal, la quinta mujer titulada en Arquitectura en 1956, colaboró en 1964 con el reconocido arquitecto Fernando Higueras en el concurso de ideas para el Teatro de la Opera de Madrid. Sin embargo su autoría de colaboración en este proyecto no suele reconocerse ${ }^{2}$. Otra de las primeras arquitectas españolas, Juana Ontañón, fue la única mujer firmante en 1953 de la relevante Manifiesto de la Alhambra pero no aparece en la foto oficial, lo que tiene como consecuencia que pocas veces se le nombre junto al resto de firmantes. Otro de los ejemplos de exclusión fue el sufrido por Denise Scott-Brown cuando el más prestigioso premio de arquitectura, el Pritzker, se otorgó en 1991 de manera individual a su marido a pesar de llevar más de 25 años firmando de manera conjunta y pública todos sus trabajos académicos y profesionales ${ }^{3}$. Podemos ver, por tanto, que trabajar junto a un prohombre de la arquitectura ha significado la exclusión de la autoría de los proyectos colaborativos y, en consecuencia, la negación de la creatividad compartida; una estrategia de

2 La página web de la Fundación Fernando Higueras no menciona la colaboración de esta arquitecta. Ver: http://fernandohigueras.org/teatro-\%C3\%B3pera Web visitada por última vez el 2020.06.22. Sin embargo, la revista Nueva Forma que dedicó un monográfico a Fernando Higueras y a su socio Antonio Miró en su No49 de Febrero de 1970 recoge la coautoría de los tres profesionales. Ver: https:/ /issuu.com/faximil/docs/1970-nf-049/44

3 Ver: https://www.metalocus.es/es/noticias/no-al-premio-pritzker-para-denise-scott-brown 
ocultación perpetuada que ha reducido la autoría de la vanguardia arquitectónica a la mitad. Menos es más que diría Mies.

Pero retomando a Griselda Pollock, queremos subrayar que no nos interesa buscar el equivalente femenino de los grandes arquitectos porque, como ella señalaba, el criterio de grandeza está ya definido por la masculinidad (1988:20). Sin embargo el ámbito de la arquitectura parece reconocerse en la actualidad como un lugar de igualdad donde las propias arquitectas colegiadas ${ }^{4}$ llegan a afirmar que «no es una profesión en la que las diferencias por sexo sean especialmente notables» (Leboreiro Amaro, 2008: 20). En otra encuesta realizada en fecha más reciente, se revela que las arquitectas «se perciben como arquitectos» y que utilizan el epiceno como seña de identidad profesional puesto que «se firman las obras con inicial y apellido, enmascarando el género del autor» (Carreiro, 2012:75). Es probable que ello tenga que ver con lo que Inés Sánchez de Madariaga señala sobre la visión tradicional de las identidades profesionales, las cuales han estado sustentadas por «mecanismos supuestamente libres de valores ideológicos» mediante el establecimiento de procesos de acceso objetivables y una evolución de la profesión en la que se desarrolla un saber hacer. Sin embargo, Madariaga puntualiza cómo las investigaciones recientes consideran «los procesos de profesionalización como una forma de control de las ocupaciones, [...] con privilegios y jurisdicciones cuidadosamente definidos» (2012b:434). Se hace necesario por tanto conocer los mecanismos de control que han caracterizado el ámbito arquitectónico tanto en la formación como en la profesión. En consecuencia, estudiaremos desde una perspectiva feminista el contexto social de creación de las instituciones arquitectónicas - Academia, Escuelas de Arquitectura y Colegios de Arquitectos- ya que ello nos permitirá detectar las redes patriarcales de apoyo endogámico y elevación social que cimentaron las bases de la enseñanza y ejercicio profesional de la arquitectura y que posicionaron a varones y mujeres de manera totalmente asimétrica en esta disciplina. Por añadidura el ejercicio de la arquitectura ha sido $-\mathrm{y}$ es ${ }^{5}$ - una disciplina que ha estado muy vinculada al Estado y al poder estamental patriarcal, ya que estos son muy conscientes del prestigio que emana de una obra arquitectónica a favor de los estamentos que la producen (Vidaurre Jofre, 1975:47) puesto que es una herramienta capaz de transmitir mensajes muy concretos (Sudjic, 2007:10).

Como se desarrollará en el texto, al revisar bajo una perspectiva feminista la creación del primer estamento arquitectónico durante el período de la Ilustración, destacaremos un cambio de vital importancia en la consideración de la Arquitectura. Los Ilustrados consideraron esta Bella Arte como un arte útil, por lo que establecieron un sistema de enseñanza superior de la misma, así como la regulación del ejercicio profesional de la arquitectura. El control y fiscalización del ámbito formativo y

4 En España la Ley obliga a pertenecer a un Colegio Oficial de Arquitectos para poder ejercer la profesión. Como se puede observar el nombre de los mismos responde al epiceno y no al genérico de Arquitectura a pesar de que las Escuelas de Arquitectura incorporaron desde el inicio el nombre de la disciplina.

5 En España el propio Decano del Colegio de Arquitectos de Madrid afirmaba en 2015 que ciertos edificios son meros «soportes publicitarios e instrumentos de comunicación política» https:/ / elpais.com/ politica/2015/08/22/actualidad/1440243746_006184.html 
laboral de la misma generó un orden profesional de carácter endogámico que se puede considerar el germen del prestigio social del arquitecto. La falta endémica de instrucción de niñas y mujeres -por voluntad de la estructura patriarcal ilustradase afianzó durante el siglo XIX con el establecimiento de la enseñanza científicotécnica en las Escuelas de Arquitectura de Madrid y Barcelona, lo que mantuvo de facto a las mujeres excluidas de la formación y profesión arquitectónicas. Una ausencia femenina que Matilde Ucelay rompió en 1936 al titularse y colegiarse en el Colegio de Oficial de Arquitectos de Madrid como la primera arquitecta en España. Una magnífica noticia que, sin embargo, no pudo desarrollarse de manera plena. El Régimen franquista no perdonó a esta arquitecta su filiación política ni tampoco su voluntad de ejercer una profesión integrada y limitada por varones por lo que la inhabilitó de por vida para el ejercicio público de la profesión. Una inhabilitación punitiva modélica que de buen seguro hizo repensar su vocación a futuras arquitectas.

\section{2.- Academia e Ilustración en España. Cuando la Arquitectura se convirtió en un Arte útil ${ }^{6}$.}

Uno de los objetivos esenciales del nuevo estado ilustrado estaba dirigido a arrebatar el control de la formación y del ejercicio arquitectónicos de las manos de los herméticos gremios medievales para poder hacerse con el control de la arquitectura (García Melero, 1991:284). El Ministro ilustrado Campomames manifestó que el sistema gremial era un estorbo para el desarrollo de la industria ya que disponían de una legislación y de fuentes de financiación internas propias sólo conocidas y divulgadas exclusivamente entre los gremios (Ruiz de Ael, 1993:53). El paso decisivo en la consecución de dicho objetivo fue la creación de la Real Academia de Bellas Artes de San Fernando en Madrid en $1752^{7}$. Todo aquel que aspirara al ejercicio profesional de la arquitectura debía formarse en esta nueva institución. Por añadidura, la Academia de San Fernando se convirtió en la primera institución de regulación de la arquitectura en España, centralizando por primera vez enseñanza y formación, habilitación y regulación de los profesionales (Capel, 2005:8), así como difusión de las teorías y pensamiento arquitectónicos. El papel preponderante de la institución se aseguró con los Estatutos de 1757 donde la academia de Madrid establecía que era la única institución - sobre otras academias

6 La Real Sociedad Bascongada de Amigos del País y de las Artes se organizó mediante cuatro comisiones. Así la comisión segunda estaba dedicada a las ciencias y artes útiles, que es donde se ubicará la Arquitectura, mientras que la Escultura, el Dibujo, así como el resto de las artes que se vienen a llamar menores, corresponderán a la comisión cuarta, dedicada a la historia, política y buenas letras (Ruiz de Ael, 1993). De ahí que se haya tomado como referencia la Arquitectura como Arte útil para nombrar este apartado.

7 Fundada durante el reinado de Fernando VI. A partir de la creación de la Real Academia de Bellas Artes de San Fernando surgieron otra serie de academias como la de San Carlos de Valencia o la de San Luis de Zaragoza. (Honour, 1982:9-45). La Academia tenía tres secciones: Escultura, Pintura y Arquitectura pero fue en el terreno de la arquitectura donde la Academia de San Fernando centró fundamentalmente su trabajo hasta convertirse en objetivo primario de la institución 
que se crearan en España- que podía dar el título de Arquitecto. El objetivo era claro: sólo ofreciendo una enseñanza de calidad se podía luchar contra el poder de los gremios y, al mismo tiempo, controlar lo que se edificaba en España gracias a arquitectos formados en la Academia y, por tanto, de su total confianza (Garcia Melero, 1991: 293). La secuencia arquitectónica Gremio, Academia y Escuela (Navascues, 2004:13) daba de esta manera por finalizado la primera de sus etapas. Una etapa en la que las mujeres accedían a la construcción de la arquitectura gracias a heredar un taller gremial de la construcción, aunque sólo hasta que un hijo varón pudiera hacerse cargo del mismo. Hasta entonces, la presencia de mujeres a pie de obra aparece documentada en la clasificación de los obreros por gremios en los Contratos de Obras o Libros de Expensas: carpinteros, canteros, peones, guías de bueyes y, en el escalafón más bajo de todos ellos, las mujeres ${ }^{8}$.

La Ilustración no vio el arte como la más alta y pura expresión de la cultura, sino que más bien lo vinculó a una tendencia utilitaria. Esto dio lugar a un profundo cambio al ser considerada la Arquitectura de gran relevancia debido a su importante componente económico consolidando esta disciplina como un Arte útil (Ruiz de Ael, 1993:24-25). Un cambio de paradigma que, siguiendo a Jo Freeman, podemos parafrasear como la consideración de que la arquitectura era un trabajo importante para los ilustrados. Siguiendo esta premisa podemos inferir que este trabajo importante estaba dirigido exclusivamente por y para los hombres de la Ilustración ya que «El primer concepto central del pensamiento sexista es que los hombres hacen el trabajo importante en el mundo y que el trabajo hecho por los hombres

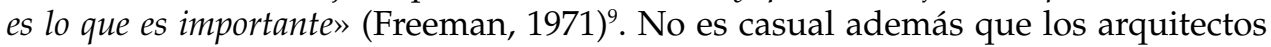
pertenecientes a la Real Academia de San Fernando fueran, por una parte, los agentes de una institución absolutamente centralizada y, por otra «embajadores, consejeros reales, sumilleres, gentilhombres de cámara, mayordomos de su majestad, altos grados militares y jerarquías eclesiásticas que, con los académicos de honor, representaban el verdadero poder de la Academia» ${ }^{10}$. La Academia y el poder político ilustrado estaban absolutamente relacionados generando una red de prohombres -estructura del orden estamental patriarcal- que controlaban y fiscalizaban todo lo relativo a la arquitectura. La Academia de San Fernando filtraba de manera rigurosa desde 1786 «todos los proyectos de construcción financiados con fondos públicos» (Barrio Loza, 2002: 18). El estamento a través del cual se fiscalizaban dichos proyectos era la Comisión de Arquitectura, el órgano censor de la España ilustrada creada en 1786 por la Academia y habilitado por la Corona para aprobar, modificar o reelaborar proyectos de obra pública. De esta manera, la Comisión -o mejor dicho los arquitectos

8 Podemos encontrar mujeres a pie de obra en la ejecución de un camino en 1549 en la localidad guipuzcoana de Hondarribia cuyo trabajo consistía en retirar escombro y acarrear agua a la obra. En Navarra existe registro de mujeres en 1350 retirando tierra y escombros. Generalmente no se les cita por su nombre sino que aparecen señaladas como «la mujer del cantero»o «la hija de» (Crespo y Ciordia, 2020: 15-16). La publicación «Arquitectura y mujeres en la historia» de María Elena Díez Jorge aporta asimismo excelente documentación sobre el papel histórico de las mujeres a pie de obra 9 en España o como mecenas en la arquitectura.

10 http:/ / www.realacademiabellasartessanfernando.com/es/academia/historia 
miembros de ella- podían modificar el proyecto presentado e incluso sustituir al arquitecto autor por otro profesional de su confianza (Sambricio, 2020: 110-111). Por añadidura, al segregarse la Arquitectura del resto de prácticas artísticas tenía más peso específico que los escultores, pintores o grabadores académicos por lo que los arquitectos gozaban de más sueldo y más encargos y, por ende, de más prestigio (Garcia Melero, 1997). La Comisión de Arquitectura se convertía así en un estamento que facilitaba la elevación y diferenciación social del arquitecto. El germen de la élite profesional comenzaba por tanto a gestarse en el corazón de la institución de enseñanza de la arquitectura, esto es, en la Real Academia de san Fernando.

En este contexto de poder y elevación social la exclusión femenina era obvia puesto que, además, las mujeres sufrían de manera sistemática por parte del orden social patriarcal una instrucción diferenciada que las había alejado de cualquier pretensión de formación reglada. La Ilustración consideró a la mujer como un ser útil y, por tanto, digna de educación (Ortega López, 1988: 306). Sin embargo, esa educación tenía como objetivo cumplir las obligaciones derivadas de su clase social pero, en ningún caso, formar su inteligencia tal y como lo hacían los varones (Capel Martínez, 2010: 6). Los ilustrados «participaban plenamente de la idea de la desigualdad de los sexos por naturaleza y de que la educación debía mantener esa desigualdad» (Recarte Barriola, 1992: 321) aunque abogaban por mejorar su instrucción a través de la introducción de, entre otras materias, el Dibujo. Aun siendo una disciplina que podía considerarse afín a lo considerado como femenino, los próceres de la Ilustración eran muy conscientes del valor que tenía el dibujo en el sistema gremial ${ }^{11}$ y de su función como lenguaje universal (Ruiz de Ael, 1993: 33). Sin embargo, el objetivo fue desterrar el conocimiento gráfico monopolizado por los gremios y no incorporarlo a la formación de mujeres y niñas. Sabemos que algunas mujeres de estatus social elevado tuvieron acceso limitado a formarse en la Real Academia de Bellas Artes de San Fernando pero únicamente en las secciones de Dibujo y Pintura y no como profesionales sino como aficionadas ${ }^{12}$. No hubo mujeres escultoras ni arquitectas dentro de la institución. Bajo una ilusoria igualdad los prohombres ilustrados no considerarán la instrucción de las mujeres como prioritaria y, a pesar de ser instruidas algunas mujeres (pocas, muy pocas) en Dibujo, estas nociones no pasarán de meros rudimentos orientados al cuidado doméstico y, por tanto, alejados del ámbito arquitectónico.

11 Existía una figura dentro del gremio de canteros que se solía denominar como arquitecto por facilitar las trazas en obras concretas y por tanto atribuírsele dichas obras (Barrio Loza, 1980:296). La competencia de trazar, esto es, de proyectar y dibujar los planos, denotaba una competencia saber y dominio de la Geometría y por tanto de gran relevancia dentro del propio gremio, el cual era un oficio de escasa formación teórica que seguía formas eminentemente prácticas, diferenciando y cualificando jerárquicamente al maestro tracista.

12 Se documentan más de 50 mujeres, fundamentalmente damas, que tuvieron título de mérito o de honor durante el primer siglo de historia de la Real Academia. Las mujeres no podían ingresar como alumnas en la Real Academia ni podían acceder a puestos de relevancia, pero hubo algunas que lograron ser miembros oficiales por otras vías. En https://www.investigart.com/2019/11/26/ mujeres-academicas-en-la-real-academia-de-bellas-artes-de-san-fernando / 
De la importancia del Dibujo para los Ilustrados dan cuenta instituciones como las Sociedades Económicas dentro de las cuales se crearon Escuelas gratuitas de Dibujo. De esta manera la Real Sociedad Bascongada de Amigos del País y de las Artes -que fue la primera que se fundó en España en 1764- creó las Escuelas gratuitas de Dibujo ${ }^{13}$ y el Real Seminario Patriótico de Vergara $^{14}$, donde se formaba a futuros aspirantes a arquitecto y a agentes de la construcción respectivamente. Es de subrayar que el poder de la Bascongada no fue en ningún caso territorial sino estatal puesto que la mayor parte de los socios bascongados formaban parte de la Real Academia de Bellas Artes de San Fernando ${ }^{15}$. En consecuencia, la influencia de esta sociedad económica distaba mucho de ser provincial, surgiendo desde el núcleo de poder más elevado de la Ilustración española -los secretarios de la monarquía -y alcanzando los máximos estamentos de poder del mismo.

Como podíamos suponer no podremos encontrar mujeres en las Escuelas de Dibujo ni en el Seminario de Vergara ${ }^{16}$. Tampoco en la Sociedad Bascongada como socias de pleno derecho. De hecho fue uno de los socios bascongados, Francisco Cabarrús, quien consideraba a las mujeres «incompetentes y charlatanas» y de «naturaleza frívola», el que sostuvo la conocida polémica en 1786 con Jovellanos sobre el desorden que traería la inclusión de mujeres en las Reales Sociedades Económicas (Calderón España, 2010: 192). Otro de los socios de la Bascongada fue Eugenio Llaguno quien redactó las conocidas Noticias de los arquitectos y arquitectura de España desde su Restauración ${ }^{17}$, consideradas por la historiografía como la primera

13 La arquitectura dentro de las Escuelas de Dibujo bascongadas era entendida como una formación básica, de principios, con objeto de que el estudiante se perfeccionara posteriormente en la Real Academia de Bellas Artes de Madrid. Bérchez comenta a este respecto: «Una de las parcelas menos conocidas del academicismo artístico español en el siglo XVIII, es la gestación de las academias locales y la de su paulatino entronque con el modelo de academia ilustrada que en los años setenta comenzó a desenvolverse por la influencia de la Academia de San Fernando» (Berchez, 1987:19).

14 La enseñanza de la arquitectura en el Seminario de Vergara estaba dirigida a proporcionar al país maestros bien formados cuyo cometido era realizar obras de menor carácter, como edificios particulares, fuentes, caminos públicos obras de agua. (Ruiz de Ael, 1993: 245-246)

15 De los 66 consiliarios miembros de la Academia madrileña, 10 eran socios de la institución vasca. Pero lo más significativo es que los socios bascongados y sus familias formaban parte de la élite administrativa, burocrática, política y militar de la monarquía española desde mediados del siglo XVIII. El establecimiento de dinámica de redes familiares con el objetivo de situarse y perpetuarse en la construcción del nuevo Estado administrativo, militar y financiero que la monarquía borbónica estaba impulsando fue uno de sus principales objetivos (Imizcoz y Chaparro, 2009: 996)

16 Ruiz de Ael en su completa investigación sobre las Escuelas de Dibujo de la Bascongada recoge el listado completo de los alumnos, profesores y Directores de la misma. (Ruiz de Ael, 1993:411-438).

17 El texto nació como respuesta al requerimiento que José Nicolás de Azara, embajador español en Roma en 1784, realizó a su amigo el alavés Eugenio LLaguno y Amirola. Azara era conocedor de la reciente publicación por parte de Francesco Milizia, del tratado de arquitectura «Vite de'p iúcelebriarchitettid'ognizanione e d’ogni tempo» que no incluía ningún arquitecto español. Para solventarlo encargó a Llaguno "una relación de arquitectos españoles y un análisis descriptivo de sus obras más señeras» (Cera, 2016: 249). Fue en 1829 cuando Juan Agustín Ceán Bermúdez, protegido de Melchor de Jovellanos, publicó el manuscrito con algunas modificaciones y ya firmado por el propio Ceán y Eugenio Llaguno. (Ruiz De Ael, 1993:327). El libro en facsímil con las aportaciones de Ceán Bermúdez está disponible en el siguiente link: https://bibliotecavirtual.asturias.es. 
recopilación de arquitectos de España. Tampoco encontraremos nombres femeninos en las Noticias.

La educación de la mujer que abordó la ilustración española partió desde el orden patriarcal establecido (Pérez Cantó, 2007) y fue dictada por planteamientos políticos y económicos más que por un objetivo de desarrollo de la capacidad intelectual femenina (Ortega López,1988). Voces ilustradas de gran peso como la del ministro y socio bascongado Campomames, valoraban que «La mujer tiene el mismo uso de razón que el hombre» pero sin embargo eran favorables a un sistema de educación diferenciada entre niñas y niños. Esa educación diferencial inicial lleva implícita una futura organización del trabajo completamente segregada entre hombres y mujeres. Una segregación de la que eran conscientes los prohombres ilustrados, sabedores de «que el tipo de educación que se recibe de niño está estrechamente relacionado con las ocupaciones que se desempeñan como adulto» (Sarasua, 2002:293). Una educación orientada a la utilidad del Estado y, por tanto, dirigida a las ocupaciones que el gobierno estableciera. En el sistema patriarcal ilustrado donde las mujeres eran consideradas incapacitadas para diseñar su vida por su minoría de edad legal, estas dependían del «estamento social del padre, marido o cualquier varón de su familia» para su tutela (Pérez Cantó, 2007: 4). Las ocupaciones de mujeres y niñas estaban por tanto dirigidas a labores útiles para el matrimonio, la procreación o la consagración a Dios.

Como hemos visto, el Estado ilustrado al excluir a las mujeres del acceso a la educación media o superior y, de manera paralela, al crear la Academia como centro de formación superior de la arquitectura y como institución de regulación de la profesión arquitectónica, estableció las bases de la exclusión de las mujeres en la formación reglada en Arquitectura. Tal y como señala Amelia Valcárcel (2001: 13-14) el currículo educativo era la llave que permitía el acceso a las profesiones. El sistema patriarcal ilustrado se afianzó a través del control y la institucionalización del ámbito arquitectónico en España, convirtiendo el ejercicio de la arquitectura en un trabajo importante cuyo acceso estaba limitado a las redes de arquitectos académicos pertenecientes a una incipiente élite profesional.

\section{3.- El afianzamiento de la élite profesional arquitectónica en la España del siglo XIX.}

Durante las primeras décadas del siglo XIX la educación de las mujeres se verá atravesada por la consideración de que esta debe ser una formación moral y que la instrucción de la mujer no es un asunto público sino privado (Ballarin, 1989: 247). La Ley Moyano establecerá en 1857 la obligación de crear escuelas públicas de niñas y de manera paralela las Escuelas Normales Centrales de Maestras. Sin embargo, la mayor parte de las escuelas españolas no disponían de los medios mínimos ni las niñas asistían puesto que su familia, la sociedad y la iglesia no lo consideraba adecuado. Ello tendrá como consecuencia un elevadísimo nivel de analfabetismo de más de un 80\% entre las mujeres (Ballarin, 1989:249). En ese contexto, el acceso en España a la universidad del siglo XIX era verdaderamente una quimera para cualquier mujer siendo, como eran la mayor parte de ellas, analfabetas y sin apenas formación básica en escritura y lectura (Sarasua, 2002: 281-297). A pesar de ello hubo 
excepciones en las que algunas mujeres pudieron acceder a estudios superiores ${ }^{18}$ en las Reales Estudios de Dibujo y Adorno, las cuales tenían su precedente en las escuelas creadas por las Sociedades Económicas del siglo XVIII.

La necesaria reforma de la Real Academia de San Fernando culminó con la segregación de la enseñanza de la Arquitectura de la misma creándose en 1844 en Madrid la primera Escuela de Arquitectura. La Escuela de Barcelona no se creó hasta 1875, siendo ambas las dos únicas escuelas existentes en España hasta $1963^{19}$. No hay registros de mujeres matriculadas durante el siglo XIX en las Escuelas de Arquitectura españolas. En la monografía publicada en 2004 sobre la creación de la Escuela de Arquitectura de Madrid el autor (Prieto González, 2004:480) señala, en base a que no había una norma expresa que prohibiera el acceso a las Escuelas de Arquitectura a las mujeres, que «todo apunta a la inexistencia de solicitudesfemeninas, más que a un hipotético veto del establecimiento a la mujer». Efectivamente, tal y como ocurría con la Real Academia de San Fernando, no parece que existiera un reglamento que explicitase la exclusión de las mujeres en la Escuela de Arquitectura. Ciertamente no fue necesario. Así lo evidencia Pilar Ballarin (1989:254) quien señala cómo hasta 1890 sólo quince mujeres de toda España -de reducidos sectores de la burguesíahabían cursado estudios universitarios lo cual, por añadidura, no implicó su reflejo en el ejercicio profesional. Los mecanismos de exclusión educativos, como se ha mencionado anteriormente, estaban enraizados en el propio sistema patriarcal ilustrado y, por tanto y de manera consecutiva, en el ámbito formativo y profesional de la arquitectura. Para Ballarin, (1989:259) también el ambiente social impulsaba anular el posible deseo de instruirse a la mujer a través del desprestigio social y la hostilidad que pudiera despertar semejante anhelo. E incluso aquellos que defendían la instrucción de niñas y mujeres y su consiguiente acceso a cualquier profesión lo hacían sólo para el caso que no tuviera marido, padre o hermano que pudiera trabajar por ellas. Sin embargo, del mismo modo que, durante el último cuarto del siglo XIX, en países como Inglaterra algunas mujeres de la burguesía trabajaron copiando planos y haciendo trabajos de dibujo (Muxí Martínez, 2018: 135) bien pudiera ser que en España ocurriera de forma similar.

El acceso al título de arquitecto en la España del siglo XIX implicaba disponer no sólo de un alto nivel de conocimientos científico-técnicos sino también de un largo periodo de tiempo de formación, lo que conllevaba un gasto económico desmesurado que pocos varones -y menos aún mujeres- podían permitirse (Ocerin Ibáñez, 2016: 109). Para entender el nivel de conocimientos previos necesarios basta con enumerar las asignaturas que el alumnado debía tener cursado y aprobado de manera antes de acceder a la Escuela de Arquitectura: Aritmética, Algebra, Geometría, Secciones Cónicas, Física y Química general, Dibujo, Paisaje y Adornos.

18 Destaca el conocido caso de Concepción Arenal que asistió a la Facultad de Derecho de Madrid vestida de varón.

19 En 1963 se creó en España la primera Escuela de Arquitectura ex novo, la de Sevilla, gracias a la aprobación de la Ley de Enseñanzas Técnicas de 1957 cuyo objetivo era generar técnicos que ayudaran en el desarrollo del país. La política de creación de nuevas Escuelas Técnicas de Arquitectura tuvo como consecuencia el aumento exponencial de arquitectos egresados y, por tanto, el principio del fin de la pertenencia a una élite social y profesional (Ocerin Ibáñez, 2016: 216-223). 
Una vez aprobadas el total de estas ocho asignaturas, y junto con el certificado que lo demostrase, se accedía a la Escuela de Arquitectura donde se cursaban otros cinco años de enseñanza y un tiempo adicional de prácticas (Navascues, 1973). En consecuencia, el tiempo de formación podía alcanzar mínimamente los siete u ocho años y alargarse más allá de los diez. Una longitud excesiva que encarecía la enseñanza y que, junto con el numerus clausus existente, dificultaron el ingreso en las Escuelas de Arquitectura lo que dio como resultado un escaso número de egresados (Navascues, 1990: 30). Por añadidura este contexto social con un reducido número de varones que lograban acceder a la profesión arquitectónica conllevaba una inmejorable ventaja al convertirse los egresados en parte de una de la élites sociales y profesionales de mayor prestigio. El establecimiento de esta élite de los arquitectos se debió también a que el ejercicio de la arquitectura en el siglo XIX comenzó a ser uno de los negocios de la burguesía (Vidaurre Jofre,1975: 49). Confort y formación técnica, aspectos de los que adolecía la Academia, fueron las nuevas demandas burguesas en formación arquitectónica. La burguesía ilustrada del último tercio del siglo XIX exigió a «los centros encargados de "producir» artistas técnicos, un mayor nivel de adecuación con ellas, con el solo objeto de que estos cumplan con mayor eficacia la función que ella les encomienda». Este proceso de colaboración con las clases altas y poderosas sería una de las vías por las que los arquitectos adquirieron la categoría de una de las «oligarquías del poder cultural y como tal, se van constituyendo en un grupo cerrado, de élite, en el que cada vez es más difícil el acceso, como defensa de la situación de privilegio que van conquistando» (Vidaurre Jofre, 1975: 55). Una profesión que en España se cimentaba en base a unos estudios superiores a los que pocos hombres podían acceder y que, en el contexto del analfabetismo endémico femenino, eran absolutamente inaccesibles de facto para las mujeres españolas del siglo XIX.

Durante el siglo XIX se gestaron además los Ensanches de las ciudades más importantes de España como Madrid o Barcelona y el arquitecto se convirtió en el colaborador imprescindible para la creación de la imagen urbana (Vidaurre Jofre, 1975: 50). El elevado desarrollo constructivo decimonónico tanto de edificios de viviendas como de edificios institucionales, dio lugar a que «arquitectos, aparejadores y delineantes no daban abasto ante una ciudad que estaba en plena expansión y remodelación» (Carballo Barral, 2012:15). Es también cuando se dio la incorporación de los arquitectos a la función pública y por tanto se formalizaron los puestos laborales de los arquitectos en la Administración (Mas Serra, 2001). No debemos olvidar que el Estado era el que gestionaba un buen presupuesto y era el agente promotor de la mayoría de las grandes obras de la ciudad que, a su vez, son las que daban reconocimiento y prestigio al arquitecto. De esta manera surgieron nuevas modalidades profesionales: los arquitectos municipales, provinciales, diocesanos, arquitectos restauradores, etc (Ocerin Ibáñez, 2016: 140-157). Los emolumentos que podían llegar a recibir estos arquitectos funcionarios en diferentes cargos en la administración de finales del siglo XIX junto con su ejercicio profesional liberal dan cuenta de la elevada posición económica de la que gozaban estos profesionales (Navascues, 1990:30). 
El consecuente prestigio social de los arquitectos y la absoluta masculinización del ámbito profesional y formativo de la Arquitectura en España -un hecho forjado en el corazón de la Academia, una de los estamentos patriarcales de la Ilustraciónse mantuvo tras la creación de las Escuelas de Arquitectura y se reforzó con el afianzamiento del arquitecto varón como figura de prestigio socio-profesional. El contexto de institucionalización del ejercicio de la arquitectura dentro del inalterable sistema patriarcal, unido a la falta de instrucción y a los altos niveles de analfabetismo en la población de mujeres y niñas imposibilitaron el acceso de las mujeres a la formación superior en Arquitectura; una formación que hubiera asegurado una profesión y con ello el consecuente avance femenino en lo social, cultural y económico.

\section{4.- Noticias de Matilde Ucelay. La prohibición del ejercicio público de la profesión al primer «arquitecto femenino $»^{20}$.}

A principios del siglo $\mathrm{XX}$, el nivel de analfabetismo entre las mujeres españolas seguía siendo muy alto superando el 70\% en 1900 (Ballarin, 1989:249). Este contexto seguía marcando como no podía ser de otra manera los límites profesionales de las mujeres. El disponer de una titulación a principios del siglo XX en España era una de las pocas oportunidades para subir en el escalafón social puesto que permitía unos ingresos que doblaban los de cualquier empleado o trabajador además de representar un prestigio público importante (Carballo Barral, 2012: 16). Recordemos que en España a principios del siglo XX sólo existen dos Escuelas de Arquitectura: la más antigua, la de Madrid, fundada en 1844; y la de Barcelona fundada en 1875. Estos dos centros egresaban un reducidísimo número de arquitectos. Así durante las primeras décadas del siglo XX entre la Escuela de Madrid y la de Barcelona el número de titulados anualmente no superaba los cincuenta egresados (Ortega Vidal y Rivas Quinzaños, 2019) siendo un total aproximado de mil arquitectos en toda España ${ }^{21}$. Más de la mitad de los arquitectos se concentraban normalmente en Madrid y Barcelona por lo que en el resto de provincias había muy pocos profesionales. Ello, obviamente, permitía a los arquitectos acceder a un amplísimo volumen de trabajo y a una diversa carta de clientes que incluía de manera habitual tanto a la Administración pública como clientela privada. En consecuencia, los arquitectos disfrutaban de un inmejorable mercado laboral que les mantenía en un exclusivo estatus profesional, social y económico.

Es también en estos momentos cuando se crean los Colegios Oficiales de Arquitectos $^{22}$ en España. Este será otro de los puntos de inflexión en la profesión

20 Se hace referencia al título del artículo publicado en el Periódico La Voz el 3 de Julio de 1936 sobre Matilde Ucelay «El primer arquitecto femenino que tiene España...» Citado por (Vílchez Luzón, 2014: 194).

21Datos del Consejo Superior de Colegios de Arquitectos de España. Ver: http://www.cscae.com/ index.php/colegios-arquitectos60

22 El Consejo Superior de los Colegios de Arquitectos de España, creado en 1931, es el organismo que reúne a todos los Colegios de Arquitectos de España. En 1933 se crearon seis colegios oficiales con tan sólo 353 colegiados del total de 995 arquitectos (todos varones) existentes en toda España. En la actualidad hay veintisiete colegios oficiales y cerca de cincuenta mil arquitectas y arquitectos colegiadas. 
arquitectónica, puesto que a partir de entonces los Colegios Oficiales de Arquitectos se convierten en las instituciones a las que debe pertenecer toda persona titulada en arquitectura que quiera ejercer la profesión ${ }^{23}$. Ello conformará un colectivo profesional consciente de ser una «clase [...] privilegiada» ${ }^{24}$ y que, en 1933, aún estaba constituido totalmente por varones ${ }^{25}$.

En ese contexto será cuando en 1931 Matilde Ucelay, Lali Urcola y Cristina Gonzalo $^{26}$ ingresen en la Escuela de Arquitectura de Madrid. Teodoro de Anasagasti, arquitecto y profesor en la Escuela de Arquitectura de Madrid les hará su particular recibimiento desde un artículo en la prensa lanzando la pregunta: «Las mujeres en la arquitectura ¿valen para esta profesión?» ${ }^{27}$. Y, aunque resulte anecdótico, es posible que en este artículo Anasagasti sea uno de los primeros que se refiera a Matilde Ucelay como arquitecta sin usar el epiceno masculino. Este arquitecto y profesor ya había reflexionado en 1923 sobre la presencia de las mujeres en arquitectura, gracias a las visitas que realizó a Escuelas de Arquitectura de otros países, donde encontró mujeres subidas a andamios «no para transportar materiales y acompañar al hombre, como en el Norte de nuestra Península, sino para competir con él en los oficios de la construcción». En concreto, el arquitecto describía su visita a la Escuela Politécnica de la Universidad de Munich, donde las alumnas «manejan con desenvoltura el compás y la escuadra» lo que para el arquitecto hace «posible que en nuestros Congresos internacionales las veamos pronto, no en calidad de asociada, sino como miembro titular» (Anasagasti, 1923:10).

Matilde Ucelay será la primera de ellas en España al titularse en 1936 en la Escuela de Arquitectura de Madrid. Ella era una de las excepciones que pertenecía al pequeño porcentaje femenino que tuvo una instrucción reglada y de calidad ya que su padre y su madre provenían ambos de familias cultas relacionadas con intelectuales (Sánchez de Madariaga, 2012a: 11). Su vocación temprana es de resaltar puesto que «A los once años ya decía que quería ser arquitecta. Decía que los arquitectos no sabían cómo se vivía en las casas y que hacía falta que ella fuera arquitecta para hacerlas bien» (Sánchez de Madariaga, 2012a: 7). Un objetivo y una vocación que, no obstante, no podrían llenarse de manera plena. Y es que no es casual que, nada más finalizada la

23 Real decreto de 27 diciembre de 1929: "Será condición obligatoria para el ejercicio de la profesión de Arquitecto en España, además de la posesión del correspondiente título académico, el hallarse incorporado a un Colegio de Arquitectos».

24 Artículo «Nuestra colegiación» en Boletín del Colegio Oficial de Arquitectos Vasco-Navarro, 1930.

25 La situación no era mejor en el resto de asociaciones profesionales arquitectónicas de Europa. En Alemania en 1938, como señala la arquitecta Carmen Espegel (2006: 97) «había sólo 7 mujeres entre los 11.825 miembros de la Asociación Alemana de Arquitectos». Incluso en Francia se hubo de fundar en 1963 una institución profesional paralela -la Union Internationale des Femmes Architectes- puesto que la International Association of Architects no admitía arquitectas (Espegel, 2006: 92).

26 Cristina Gonzalo (titulada en 1940), Juana de Ontañón (1940), Rita Fernández Queimadelos (1941), Margarita Mendizabal (1956), Maria Eugenia Pérez Clemente (1956), Elena Arregui (1958), Milagros Rey (1960), Margarita Brender Rubira (1962) y Ma Mercedes Serra Barenys (1964) han sido las diez primeras arquitectas tituladas en España.

27 Ver «Las mujeres en la arquitectura: ¿Sirven para esta profesión?», Blanco y Negro, 21 Febrero 1936, N47. Reproducido en (Sánchez de Madariaga, 2012: 32). 
guerra, el poder franquista interviniese el ámbito de la profesión arquitectónica ${ }^{28}$. La Arquitectura es considerada un trabajo importante por el poder gubernamental por lo que debe estar bajo estricto control y regulación. Así, durante al menos diez años desde 1939, la designación de los órganos colegiales quedó en manos de los órganos políticos (Alonso Pereira, 1982:33). La dramática coincidencia de la titulación de Matilde Ucelay en 1936 con su manifiesta adscripción política contraria al golpe de estado franquista (Madariaga, 2012a:39) generó uno de los castigos ejemplarizantes más duros del sistema franquista para con los profesionales de la arquitectura. Fueron los propios Colegios profesionales los que desarrollaron «una intensa labor punitiva sobre los arquitectos desafectos al nuevo Régimen» (Alonso Pereira,1982:32). Esa «labor punitiva» se ensañará con Ucelay con el objetivo de silenciar su futuro profesional pero también como aviso ejemplar a futuras arquitectas. Su perfil de mujer culta, independiente y profesional en un ámbito de tal importancia para el orden patriarcal franquista debía pasar desapercibido para aquellas que buscaran referentes en el absolutamente masculinizado espacio de la arquitectura española.

Matilde Ucelay fue castigada por el estamento profesional en el que estaba colegiada con la inhabilitación a perpetuidad para cargos públicos o de confianza. En consecuencia, Ucelay nunca pudo ejercer de arquitecta municipal en ningún ayuntamiento, ni pudo realizar planeamientos urbanísticos de la administración, ni pudo construir ningún edificio público. A Matilde Ucelay se vetó su participación profesional en la vida pública negando su derecho a comunicar su arquitectura. Su identidad profesional quedó de esta manera cercenada y limitada al ámbito privado. El castigo, sin duda, consiguió su objetivo: ninguna arquitectura pública recordaría con su presencia física a la primera arquitecta titulada en España. Esta estrategia franquista de silenciación y ocultación para con la arquitecta -compartida y ejercida, recordemos, desde los Colegios Oficiales de Arquitectos- fue dirigida asimismo a coartar su ejercicio privado de la profesión: se le prohibió ejercer durante cinco años, no expidiendo su título hasta 1946, y eliminando su nombre de la lista pública de arquitectos españoles hasta finales de la década de los cuarenta. Una eficaz manera de silenciar tanto su nombre como la autoría de sus primeras obras arquitectónicas, las cuales quedaron escondidas bajo la firma de colegas que ayudaron a la arquitecta firmando esos primeros proyectos (Sánchez de Madariaga, 2012a:75). Un efectivo castigo ejemplarizante para aquellas mujeres que dirigieran su mirada y anhelo vocacional hacia la figura de la primera arquitecta española.

28 En 1939 se crea la Dirección General de Arquitectura dentro del Ministerio de Gobernación con el objetivo de asumir el control del ejercicio profesional de la arquitectura en su totalidad. Se nombró por disposición gubernativa al Decano del Colegio de Arquitectos de Madrid y al Presidente del Consejo Superior de Arquitectos de España (García Morales, 1975: 61-63). 
A pesar de ello, Ucelay estableció su propio estudio de arquitectura y a partir de 1940 pudo firmar sus propias obras llegando a desarrollar más de 120 proyectos para clientes privados. La mayor parte de esos proyectos, sobre todo los iniciales, fueron casas para familias de la alta sociedad madrileña. La participación en la vida pública de la primera arquitecta española quedó coartada en dos vertientes, la profesional -cercenada de por vida y limitada al ejercicio privado- y la personal, en la que tuvo que esconder su perfil de arquitecta, aunque ello le llevara a vivir de manera esquizofrénica por ser «extremadamente difícil, trasladar lo profesional a su condición de mujer.» (Sánchez de Madariaga, 2012a:88).

Matilde Ucelay fue por añadidura una mujer generosa que ayudó a sus compañeras y defendió aquellos derechos que consideraba legítimos. Así, otra de las primeras arquitectas tituladas en España, la irunesa Elena Arregui, recordaba cómo Ucelay le acompañó a buscar una academia de Dibujo para poder preparar el acceso a los cursos de ingreso a la Escuela de Arquitectura de Madrid. Cuando ambas se dirigieron a la mejor academia de Dibujo de Madrid les recibieron a la manera que Le Corbusier recibió a Charlotte Perriand: "Aquí no se admiten mujeres para prepararse para Arquitectura: ni trabajan ni dejan trabajar» (Carreiro y López, 2016: 64-65). Obviamente ello no fue óbice para que las dos mujeres buscaran otra academia donde pudiera formarse la joven Elena Arregui. Más adelante, Ucelay reunió a las arquitectas que ya ejercían la profesión para forzar la modificación de la normativa de la Hermandad Nacional de Arquitectos ${ }^{29}$. Este antiguo sistema de pensiones -nacido en el seno de los Colegios de Arquitectos- consideraba a las mujeres únicamente como esposas o viudas de arquitectos, pero no como profesionales. En consecuencia, no preveía baja laboral motivada por parto ni pensión de viudedad a favor del marido ${ }^{30}$. Las arquitectas en activo no eran, por tanto, siquiera consideradas profesionales de pleno derecho como el resto de colegas varones. Otro ejemplo de la destacada prevalencia del sistema patriarcal en el seno de la profesión arquitectónica.

La figura profesional, y por tanto pública, de Matilde Ucelay se recuperó en parte en 2004 cuando la arquitecta recibió el Premio Nacional de Arquitectura. También los Colegios Oficiales de Arquitectos realizaron ese mismo año un acto simbólico y absolutamente necesario de recuerdo y desagravio hacia la arquitecta y los compañeros depurados -y castigados- por las Juntas de sus propias instituciones profesionales.

29 La Hermandad Nacional de Arquitectos (HNA en la actualidad) era en sus inicios un montepío colegial al modo de un sistema de previsión social de pensiones que era obligatorio para el colectivo de arquitectos y que les aseguraba a ellos o sus familiares en caso de invalidez, ancianidad, paro profesional o fallecimiento. Fue creada por el arquitecto franquista Pedro Muguruza en 1944 (García Morales, 1975: 63). La Hermandad Nacional de ARquitectos funcionaba con cuotas solidarias que se aportaban aplicando un porcentaje del coste de los proyectos visados con el que se cubría la jubilación y la cobertura sanitaria de los arquitectos. En la actualidad es una «entidad privada sin ánimo de lucro que opera en exclusiva para cubrir la previsión social, ahorro, salud y seguro de los arquitectos y de las personas de su entorno». Ver: https:/ / www.hna.es/la-mutualidad/quienes-somos.

30 Una situación que el marido de Matilde Ucelay también denunció (Carreiro y López, 2016: 79). 


\section{5.-Conclusiones}

A lo largo del artículo se ha fijado la atención en el surgimiento de las instituciones de formación y profesión arquitectónicas desde que se fundó la Real Academia de San Fernando en 1752. Una institución creada ex profeso en -y desde- el Despotismo ilustrado que reguló y se hizo cargo de la enseñanza del Arte útil -o trabajo importante que diría Jo Freeman- de la Arquitectura. Los miembros académicos formaban parte activa de los estamentos patriarcales de poder a la vez que participaban de los ideales de la Ilustración por lo que la exclusión femenina de la enseñanza superior era algo compartido. Excluido por tanto un amplio espectro de la población, la endogamia masculina -una de los cimientos de la estructura patriarcal- y el control arquitectónico del contexto académico y de la arquitectura pública -cristalizados en la Comisión de Arquitectura- tuvieron como deriva natural el germen de la elevación social de la figura profesional del varón arquitecto. Un prestigio social que se afianzó durante el siglo XIX gracias a la creación de las Escuelas de Arquitectura como centros científico-técnicos de acceso restringido, mediante numerus clausus y una duración excesiva, y a la aparición de diversas formas de ejercer la profesión en la administración. Junto con este contexto, la falta endémica de instrucción de niñas y mujeres -por voluntad del Despotismo Ilustrado y mantenido por el sistema patriarcal del siglo XIX- excluyó de facto a las mujeres de la formación y profesión arquitectónicas. El inicio del siglo XX, con la matriculación en la Escuela de Arquitectura de Madrid de Matilde Ucelay y otras compañeras y la formalización de las instituciones profesionales de los Colegios Oficiales de Arquitectos, auguraba romper con más de ciento ochenta años de ausencia de arquitectas. Una ruptura que Matilde Ucelay hizo efectiva en 1936 convirtiéndose en la primera arquitecta titulada en España. Una fecha histórica y fatídica como sabemos. Los Colegios profesionales castigaron a esta arquitecta de manera ejemplarizante cercenando su derecho a ejercer la profesión de manera pública y dificultando de manera minuciosa su ejercicio profesional en el ámbito privado.

Podemos afirmar por tanto que el ejercicio de la profesión arquitectónica y la formación reglada arquitectónicas en España, referidas ambas al período definido desde 1752 hasta 1936, han compartido el carácter endogámico entre varones y la cercanía al poder estamental debido a la consideración de la Arquitectura como un trabajo esencial que debe estar bajo control del sistema de poder. Ello les hizo partícipes de un sistema patriarcal perfectamente estructurado que, junto con la voluntad de alejar a las mujeres de la formación reglada, supuso que durante más de ciento ochenta años estuviéramos sin noticias de arquitectas en España.

\section{6.-Bibliografía}

Alonso Pereira, José Ramón (1982). Cincuenta años de vida colegial. Crónica y análisis de medio siglo de historia del Colegio de León, Asturias y Galicia. Block de arquitectura N33, Colegio Oficial de Arquitectos de Asturias. Disponible en: 
http: / / www.coaa.es /v_portal/inc/pdfver.asp?idcon $=2828 \& \operatorname{cod}=10036 \& c=3$ $\& s=111811005$ (Fecha de consulta: 12/06/2020).

Álvarez Benito, Paula y GALAN CONDE, José María (2007) «Laboratorios de formación. Modelos educativos descentrados». en Revista Arquitectos. N¹80, Ed. Consejo Superior de los Colegios de Arquitectos de España, pp.49a - 52b.

ÁlvAREz IsIDRo, Eva Maria. (2016).Women in architecture. 1975, 2015 [Tesis doctoral no publicada]. Universitat Politècnica de València. Disponible en: https:/ / riunet.upv.es/handle/10251/63278 (Fecha de consulta: 22/05/2020).

AnAsagAsti, Teodoro. (1923) La enseñanza de la arquitectura. Cultura moderna técnico artística. Madrid: Calpe.

Astiazarain, María Isabel. (1988) Arquitectos guipuzcoanos del siglo XVIII. Martín de Zaldúa, José de Lizardi, Sebastián de Lecuona. Donostia-San Sebastián: Diputación Foral de Gipuzkoa.

BAllarin, Pilar (1989). «La educación de la mujer española en el siglo XIX» en Historia de la educación, Vol.8, pp. 245-260.

BARrio LozA, José Angel (1980). El modo vasco de producción arquitectónica en los Siglos XVI-XVIII. Bilbao: Diputación Foral de Bizkaia.

BARrio LozA, José Angel (2002) «El urbanismo y la Arquitectura del Neoclasicismo en el País Vasco» en Ondare. Cuadernos de artes plásticas y monumentales, 21. Donostia-San Sebastián: Eusko Ikaskuntza, pp.15-45.

Bedat, Claude (1990). La Real Academia de Bellas Artes de San Fernando 1744-1808, Madrid: Gredos.

Berchez, Joaquín (1987). Arquitectura y Academicismo. Valencia: Alfons el Magnànim.

Calderón España, María Consolación (2010). «Presencia de la mujer en las Reales Sociedades Económicas de Amigos del País (1775-1808)» en Foro de educación, $\mathrm{N}^{\circ} 12$, pp. 185-231. Disponible en file:///C:/Users/usuario/ Downloads /Dialnet-PresenciaDeLaMujerEnLasRealesSociedadesEconomica sD-3600198\%20(2).pdf (Fecha de consulta: 30/03/2020).

CAPEL, Horacio (2005). «Construcción del Estado y creación de cuerpos profesionales científico-técnicos: los ingenieros de la monarquía española en el siglo XVIII». Comunicación presentada al Congreso Internacional sobre Fortificación y Frontera Marítima, Ibiza, 24-26 de octubre de 2003. Publicada en Cámara Muñoz, Alicia y Fernando Cobos Guerra (Eds.). Fortificación y Frontera Maritima. Actas del Seminario Internacional celebrado en Ibiza durante los dias 24 al 26 de octubre de 2003. Eivissa: Ajuntament d'Eivissa 2005. Disponible en http://www.ub.edu/geocrit/sv-85.htm (Fecha de consulta: 24/04/2020).

Capel Martínez, Rosa Ma (2010) «Prensa y Escritura femenina en la España ilustrada», en El Argonauta español, 7. Disponible en: https://doi.org/10.4000/ argonauta.431 (Fecha de consulta: 30/03/2020).

Carballo Barral, Borja. (2012). «El papel de los profesionales liberales en el mercado laboral de Madrid. 1900-1930». Disponible en https:/ / dialnet.unirioja. es/servlet/articulo?codigo=4716619 (Fecha de consulta: 25/05/2020).

CARreiro, María (2012). Las mujeres arquitectas de Galicia: su papel en la profesión y en la enseñanza de la profesión (el ejercicio de la arquitectura en galicia desde una 
perspectiva de género). Instituto de la Mujer. Ministerio de Sanidad, Servicios Sociales e Igualdad. Disponible en http://igualdade.xunta.gal/sites/default/ files/files/documentos/as_mulleres_arquitectas_en_galicia.pdf (Fecha de consulta: 20/03/2020).

Carreiro, Maria y López, Cándido (2016). Arquitectas pioneras de Galicia: ocho entrevistas. Universidade da Coruña, Servizo de Publicacións.

Castro Santamaría, Ana María (2002). Juan de Álava, arquitecto del Renacimiento. Salamanca: Caja Duero.

CERA, Miriam (2016). "The noticias de los arquitectos: towards a "National" definition of spanish architecture» en Journal of Art Historiography, Number 14, pp.1-16. Disponible en https://www.academia.edu/25814317/The_Noticias_ de_los_arquitectos_towards_a_National_definition_of_Spanish_architecture (Fecha de consulta: 16/03/2020)

Cera, Miriam (2016). «Patrocinio artístico en la Corte borbónica: el caso de Eugenio Llaguno y Amírola» en Las artes de un espacio y un tiempo: el setecientos borbónico / coord. por María del Mar Albero Muñoz, Manuel Pérez Sánchez, pp. 248-271. Disponible en https://dialnet.unirioja.es/servlet/articulo?codigo $=5437280$ (Fecha de consulta: 16/03/2020)

Colomina, Beatriz (2000). «Frentes de batalla E. 1027» en Revista Zehar, No44, pp.8-13.

Crespo, Cira y Ciordia, Elena (2020). Baginen. Euskal Herriko historia emakumeen bitartez. Tafalla: Txalaparta.

Espegel, Carmen (2006). Heroínas del espacio. Mujeres arquitectos en el Movimiento Moderno. Buenos Aires: Diseño Editorial, 2016. Primera edición: Colección Memorias Culturales. Ed. Generales de la Construcción, Valencia, 2006.

Fernández AlbA, Antonio (1975). Ideología y enseñanza de la arquitectura en la España contemporánea. Madrid: Tucar Ediciones.

FREEMAN, Jo (1971). «The women's liberation movement: its origins, structures and ideas». Citada por Álvarez IsIdro, Eva Maria. (2016). Women in architecture. 1975, 2015 [Tesis doctoral]. Universitat Politècnica de València. Disponible en: https: / / riunet.upv.es/handle/10251/63278 (Fecha de consulta: 14/04/2020).

García de León Álvarez, María Antonia (2005). La excelencia científica (Hombres y mujeres en las Reales Academias). Instituto de la Mujer (Ministerio de Trabajo y Asuntos Sociales), Madrid. Disponible en: http://www.inmujer.gob.es/ areasTematicas/estudios/serieEstudios/docs/88excelencientif.pdf (Fecha de consulta: 25/05/2020).

García Melero, José Enrique (1991). «Arquitectura y burocracia: el proceso del proyecto en la Comisión de Arquitectura de la Academia (1786-1808)». En Espacio, Tiempo y Forma. Serie VII, Historia del Arte, 4, Madrid, 283-348. Disponible en: http://revistas.uned.es/index.php/ETFVII/article/view /2185 (Fecha de consulta: 27/05/2020).

García Melero, José Enrique (1997). «El arquitecto académico a finales del siglo XVIII» en Espacio, Tiempo y Forma, Serie VII, Hadel Arte, T.10, 1997, p.161-216. Disponible en: http://e-spacio.uned.es/fez/view/bibliuned:ETFSerie741493DC5-1686-C49A-D9C2-86B1C9B5607A (Fecha de consulta: 27/05/2020). 
García Morales, Mariano (1975). Los Colegios de Arquitectos de España. 1932-1965. Ed.Castalia, Valencia.

Honour, Hugh. (1982). El Neoclasicismo. Madrid: Xarait.

Imízcoz, José María (2001). «El patrocinio familiar. Parentela, educación y promoción de las élites vasco-navarras en la monarquía borbónica» en Familias, Poderosos y Oligarquías, Universidad de Murcia, Murcia., pp. 93-130. Disponible en: https://www.academia.edu/26360157/El_patrocinio_familiar._Parentela_ educaci $\%$ C3\%B3n_y_promoci $\%$ C3\%B3n_de_las_\%C3\%A9lites_vasconavarras_en_la_monarqu $\%$ C3\%ADa_borb\%C3\%B3nica (Fecha de consulta: 13/03/2020).

Imízcoz, José María y Chaparro SAInz Álvaro (2009). «Los orígenes sociales de los ilustrados vascos» en Ilustración, ilustraciones. Vol. II, Real Sociedad Bascongada de Amigos del País-Sociedad estatal de conmemoraciones culturales, Donostia, pp.993-1027. Disponible en: https://addi.ehu.es/handle/10810/11243 (Fecha de consulta: 13/03/2020).

Imízcoz, José María «Prólogo» en Chaparro SAInz, Álvaro (2011). Educarse para servir al Rey: El Real Seminario Patriótico de Vergara (1776-1804), Zarautz, Servicio Editorial dela Universidad del País Vasco, 2011. Disponibleen:https:/ / webcache. googleusercontent.com/search?q=cache:CiZWgTW9vcoJ:https: / / dialnet. unirioja.es / descarga / articulo/5707583.pdf $+\& \mathrm{~cd}=1 \& \mathrm{hl}=\mathrm{es} \& \mathrm{ct}=\mathrm{clnk} \& \mathrm{gl}=\mathrm{es}$ (Fecha de consulta: 14/03/2020).

Kubler, George (1957). Arquitectura de los siglos XVII y XVIII. Ars Hispaniae Vol. XIV. Madrid: Plus-Ultra.

Leboreiro amaro, María A. (2008). «Informe Arquitectas 2008. Encuesta sobre el estado de la profesión». En Jornadas Internacionales de arquitectura y urbanismo desde la perspectiva de las arquitectas. Madrid, 2008.

Mas Serra, Elías (2001). Arquitectos municipales de Bilbao. Bilbao: Área de Cultura y Turismo, Ayuntamiento de Bilbao.

Muxí, Zaida y Montaner, Josep (2015). «La construcción del relato arquitectónico» en SUMA, N¹43, pp.112-113. Disponible en: https://www. academia.edu/23493297/LA_CONSTRUCCI\%C3\%93N_DEL_RELATO_ ARQUITECT\%C3\%93NICO (Fecha de consulta: 18/03/2020).

Muxí Martínez, Zaida (2018). Mujeres, casas y ciudades. Más allá del umbral, dprbarcelona, Barcelona.

Navascues, Pedro (1973). "Arquitectura y arquitectos madrileños del siglo XIX» en Biblioteca de estudios madrileños, XVII, Instituto de estudios madrileños-CSIC, Madrid.

Navascues, Pedro (1990). «Arquitectura española del siglo XIX: estado de la cuestión» en Anuario del Departamento de Historia y Teoría del Arte. UAM. Vol. II,pp.29-30.

Navascues, Pedro (1993). Arquitectura Española 1808-1914. Madrid: Espasa-Calpe.

Navascues, Pedro (2004). «Prólogo» en Aprendiendo a ser arquitectos. Creación y desarrollo de la Escuela de Arquitectura de Madrid (1844-1914), Madrid: CSIC, pp.13-16. 
OCERIN IBÁÑEz, Olatz (2016). «Formación y profesión arquitectónica en el País Vasco (1774-1977). Origen y evolución de la profesión de arquitecto desde el siglo XVI hasta la creación de la Escuela Técnica Superior de Arquitectura». Tesis doctoral, Universidad del País vasco/Euskal Herriko Unibertsitatea. Disponible en: https://addi.ehu.es/handle/10810/18483 (Fecha de consulta: 12/05/2020).

Ortega López, Margarita (1988) «La educación de la mujer en la Ilustración española» en Revista de educación, N ${ }^{\circ}$ Extra 1, pp.303-325. Disponible en: https:/ / sede.educacion.gob.es/publiventa/descarga.action?f_codigo_agc=512_19. (Fecha de consulta: 13/03/2020).

Ortega Vidal, Javier y Rivas Quinzaños, Pilar (2019). «La Escuela Superior de Arquitectura de Madrid en la Ciudad Universitaria 1927-1936: 75 aniversario 1936-2011» (2019). Disponible en: http:/ / oa.upm.es/56638/ (Fecha de consulta: 23/05/2020).

Pérez Cantó, Pilar (2007). «La sociedad patriarcal en el discurso ilustrado». XI Jornadas Interescuelas/Departamentos de Historia. Departamento de Historia. Facultad de Filosofía y Letras. Universidad de Tucumán, San Miguel de Tucumán. Disponible en: https://www.aacademia.org/000-108/62 (Fecha de consulta: 18/09/2020).

Pollock, Griselda (1988). Visión y diferencia. Feminismo, feminidad e historias del arte, $1^{\text {a }}$ edición. Reedición 2015. Buenos Aires: Ed. Fiordo.

Prieto González, José Manuel (2004). Aprendiendo a ser arquitectos. Creación y desarrollo de la Escuela de Arquitectura de Madrid (1844-1914), Madrid: CSIC.

RecARte BARriola, Maite (1992). "La renovación educativa en la ilustración vasca: la Real Sociedad vascongada de los amigos del país» en RIEV. Revista Internacional de los Estudios Vascos. Año 40. Tomo XXXVII. N. ${ }^{\circ}$ 2, Donostia: Eusko Ikaskuntza, pp. 315-330.

RIKWERT, Joseph (1982). Los primeros modernos. Los arquitectos del siglo XVIII. Barcelona: Gustavo Gili.

Ruiz de Ael, Mariano J. (1993). La Ilustración artística en el País Vasco. La Real Sociedad Bascongada de Amigos del País y las artes. Vitoria-Gasteiz: Diputación Foral de Álava.

SAmbricio, Carlos (1975). Silvestre Pérez, arquitecto de la Ilustración. Donostia-San Sebastián: Delegación del COAVN en Guipúzcoa.

SAmbricio, Carlos (1985). Arquitectura española de la Ilustración. Madrid: CSCAE e Ideal.

SAMbricio, Carlos (2020). «Reformas urbanas, ciudades servicio y proyectos territoriales: tres escalas de intervención en la segunda mitad del XVIII» en La mirada extravagante. Arte, ciencia y religión en la Edad Moderna. Homenaje a Fernando Marías. De CARlos, Maria Cruz; PeredA, Felipe y Riello, José (2020). Ed. Marcial Pons Historia, .

SÁnchez de MAdARIAgA, Inés (2012a) Matilde Ucelay Maórtua. Una vida en construcción. Madrid: Secretaría General técnica. Centro de publicaciones. Ministerio de Fomento. 
SÁNCHEZ de MADARIAGA, Inés (2012b) «Más allá del star-system en la arquitectura. Género y arquitectura menor» en Jornadas «Estudios urbanos, teorías y experiencias, Col-lectiu Punt 6, Barcelona, pp.433-442. Disponible en: https://punt6.files. wordpress.com/2011/03/estudiosurbanosgenerofeminismo.pdf (Fecha de consulta: $18 / 03 / 2020)$.

SARAsUA, Carmen (2002). «Aprendiendo a ser mujeres: las escuelas de ñiñas en la España del siglo XIX». en Cuadernos de Historia Contemporánea. Vol.24, 281297. P.294-295

Scott Brown, Denise (1989). "Room at the top? Sexism and the Star System in Architecture» en MAS Context (2015), Issue 27. Disponible en: https:/ /www. mascontext.com/issues /27-debate-fall-15/room-at-the-top-sexism-and-thestar-system-in-architecture/ (Fecha de consulta: 30/05/2020).

SudjIC, Deyan (2007). La arquitectura del poder. Cómo los ricos y poderosos dan forma a nuestro mundo. Editorial Ariel, Barcelona.

VAlCÁrcel, Amelia (2001). La memoria colectiva y los retos del feminismo, CEPALSERIE Mujer y desarrollo, $\mathrm{N}^{\circ} 31$.

VIDAURRE JOFRE, Julio (1975). «Panorama histórico de la enseñanza de la arquitectura en España desde 1845 a 1971» en Ideología y enseñanza de la arquitectura en la España Contemporánea. Madrid: Tucar, pp.33-92.

Vílchez Luzón, Javier (2013). Matilde Ucelay: primera mujer arquitecta en España. Tesis doctoral. Universidad de Granada, Granada.

Vílchez Luzón, Javier (2014) «Conversaciones con la arquitecta Matilde Ucelay (1912-2008)», en Arenal Revista de Historia de las Mujeres, vol.21 n. ${ }^{\circ}$ 1, pp. 191-204.

\section{7.-Web completa o sección de web:}

«Historia de la Academia» en Real Academia de Bellas Artes de San Fernando. Disponible en: http://www.realacademiabellasartessanfernando.com/es / academia/historia (Fecha de consulta: 18/03/2020).

«Mujeres en la Real Academia de Bellas Artes de San Fernando» en Investigart.

Disponible en: https:/ /www.investigart.com/2019/11/26/mujeresacademicas-en-la-real-academia-de-bellas-artes-de-san-fernando/ (Fecha de consulta: 18/03/2020).

Recibido el 30 de junio de 2020 Aceptado el 13 de octubre de 2020 BIBLID [1132-8231 (2020): 93-113] 